\title{
Predictors of high-sensitivity cardiac troponin in stable patients undergoing coronary angiography
}

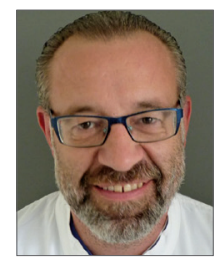

Christian M. Valina, MD; Michael Amann, MD; Christian Stratz, MD; Dietmar Trenk, PhD; Nikolaus Löffelhardt, MD; Miroslav Ferenc, MD; Franz-Josef Neumann, MD; Willibald Hochholzer*, MD

University Heart Center Freiburg - Bad Krozingen, Department of Cardiology and Angiology II, Bad Krozingen, Germany

C. M. Valina and M. Amann contributed equally to this manuscript.

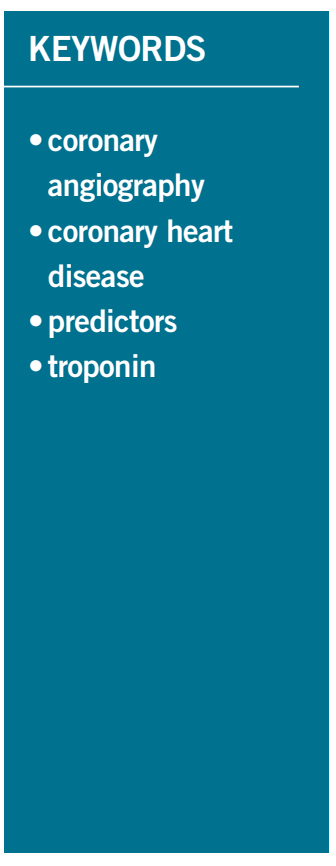

\begin{abstract}
Aims: Elevated levels of high-sensitivity troponin are seen in a significant proportion of stable patients undergoing elective coronary assessment. Multiple variables have been associated with troponin levels. The present analysis sought to identify variables independently associated with elevations of troponin and their relative strength of association with this biomarker.
\end{abstract}

Methods and results: Stable patients undergoing elective coronary angiography and echocardiographic assessment were enrolled. High-sensitivity troponin T (hsTnT) was determined before any diagnostic procedures. Multivariable linear regression models including angiographic and echocardiographic parameters were used to identify independent predictors of levels of troponin and to determine their relative contribution to levels of troponin. Out of 2,046 patients, $15 \%$ presented with levels of troponin above the upper reference limit of normal. In a combined analysis, gender followed by renal function, age, left ventricular ejection fraction, diabetes, and left ventricular mass showed the strongest association with levels of troponin. Coronary obstruction was also an independent predictor, but strength of association weakened following adjustment.

Conclusions: Up to $15 \%$ of patients undergoing coronary assessment outside the setting of acute coronary syndromes present with elevated levels of cardiac troponin. These changes are independently associated with multiple clinical, laboratory, and imaging variables. (ClinicalTrials.gov Identifier: NCT00457236)

*Corresponding author: University Heart Center Freiburg - Bad Krozingen, Department of Cardiology and Angiology II, Suedring 15, 79189 Bad Krozingen, Germany.E-mail: willibald.hochholzer@universitaets-herzzentrum.de 


\section{Introduction}

Cardiac troponin is the preferred blood marker for cardiomyocyte damage given its unchallenged myocardial tissue specificity ${ }^{1}$. For patients with acute coronary syndromes, current guidelines recommend the use of this biomarker for evaluation of diagnosis and prognosis ${ }^{2,3}$. The evolution of assays over recent years has mainly improved the sensitivity of assays ${ }^{1,4,5}$. This allows detection of troponin levels in $25-80 \%$ of stable patients depending on the highsensitivity troponin assay used ${ }^{6-8}$. Further data suggest that even low-level elevations of troponin in stable subjects are associated with an increased risk of subsequent cardiovascular events ${ }^{7-9}$. This association might be explained by the detection of subclinical and undiagnosed cardiac pathologies, such as obstructive coronary atherosclerosis, by cardiac troponin ${ }^{7,8,10}$.

\section{Editorial, see page 296}

Recent data have demonstrated that a significant proportion of stable patients undergoing elective coronary angiography present with elevated levels of troponin ${ }^{11}$. However, a significant proportion of these patients are not diagnosed with obstructive coronary heart disease since multiple factors are also associated with elevated levels of troponin such as male gender, age, renal function, pulmonary embolism, sepsis, anaemia, and diabetes mellitus. Little is known about the relative contribution of these single variables to variability in levels of troponin. It is also uncertain if some of these variables are not just surrogates of other conditions more directly related to elevations of troponin (e.g., left ventricular dysfunction as surrogate of coronary heart disease). Thus, the present analysis sought to identify independent predictors of elevations of troponin, and to analyse how strongly they are associated with levels of troponin following adjustment for invasive and non-invasive cardiovascular imaging results.

\section{Methods STUDY POPULATION}

This study represents a secondary retrospective analysis of the prospective observational EXCELSIOR trial (Impact of Extent of Clopidogrel-Induced Platelet Inhibition during Elective Stent Implantation on Clinical Event Rate; ClinicalTrials.gov Identifier: NCT00457236) $)^{12,13}$. In brief, stable patients with suspected obstructive coronary heart disease due to positive stress testing and/or typical symptoms scheduled for elective cardiac catheterisation were eligible for the study. The primary analysis investigated the impact of on-clopidogrel platelet function on the clinical outcome of patients undergoing coronary intervention. Major exclusion criteria were acute myocardial infarction (MI) with a rise and fall of cardiac troponin as defined by current guidelines ${ }^{14}$, signs of ischaemia at rest, known severe valvular heart disease, chronic oral anticoagulation, thienopyridine pretreatment, active cancer, haemodialysis, and haemodynamic instability. All patients underwent full cardiovascular assessment including electrocardiogram, echocardiography, and coronary angiography.

From 2003 to 2004, 2,053 patients were enrolled in this study. Blood samples for biomarker testing were missing from seven persons, leaving 2,046 patients for the present analysis. All patients gave written informed consent. The study was approved by the ethics committee of the University of Freiburg, Germany.

\section{LABORATORY PROCEDURES}

Blood samples for biomarker testing were collected in serum tubes after enrolment and before coronary angiography. Within one hour, samples were carefully processed and frozen at $-80^{\circ} \mathrm{C}$ until assayed in a blinded fashion in the central laboratory. High-sensitivity troponin T (hsTnT) was measured with a sandwich enzyme electrochemiluminescence immunoassay (Roche Diagnostics, Mannheim, Germany) using lot number 153401 that is not affected by the recently detected shift in the low end measuring range. This assay has a limit of blank of $3 \mathrm{ng} / \mathrm{L}$, a limit of detection of $5 \mathrm{ng} / \mathrm{L}$, a $99^{\text {th }}$ percentile of a healthy population cutoff point of $14 \mathrm{ng} / \mathrm{L}$, and a coefficient of variation of less than $10 \%$ at $13 \mathrm{ng} / \mathrm{L}^{15}$. Creatinine clearance was estimated with the use of the Cockcroft-Gault formula.

\section{IMAGING STUDIES}

Echocardiographic results, including at least basic data such as left ventricular ejection fraction and valvular status, were available from all enrolled subjects. A complete and detailed echocardiographic assessment including quantification of cardiac chamber size, ventricular mass, details of valvular anatomy, central venous filling, and estimation of pulmonary artery pressure was available from 1,072 subjects. Echocardiographic results were assessed and described according to current recommendations ${ }^{16}$. Baseline characteristics were comparable for patients with at least basic and full echocardiographic assessment. For multivariable analyses, valvular heart disease was defined as the presence of at least moderate changes at any valve.

The results of coronary angiography regarding vessels of more than $1.5 \mathrm{~mm}$ in diameter were divided into four groups according to grade of stenosis: $<20 \%$ - no or only very minor visible coronary changes; $20-49 \%$ - minimal coronary changes; $50-74 \%$ intermediate coronary obstruction; and $\geq 75 \%$ (or left main disease $\geq 50 \%$ ) - haemodynamically relevant coronary obstruction.

To analyse the extent of atherosclerotic burden in more detail, the Gensini score was calculated for all patients as previously described ${ }^{17}$. This score represents one of the most commonly used scoring systems to quantify the angiographic burden of coronary heart disease ${ }^{18}$.

\section{STATISTICS}

Discrete variables are reported as counts (percentages) and continuous variables as mean \pm standard deviation. Continuous variables with non-Gaussian distribution identified by Kolmogorov-Smirnov test were described as median (interquartile range). For discrete variables, we tested differences between groups with the $\chi^{2}$ test or Fisher's exact test when expected cell sizes were less than five. We used the two-tailed t-test to compare continuous variables, or the Mann-Whitney U or Kruskal-Wallis test for non-Gaussian variables. In the two-sided test, a p-value $<0.05$ was regarded as significant. 
Multivariable linear regression models were used to identify independent predictors of levels of hsTnT and to determine their strength of association with levels of hsTnT derived from partial $\eta^{2}$. In these models, partial $\eta^{2}$ describes the proportion of variance in hsTnT explained by a specific variable. Levels of hsTnT at presentation were entered as dependent variable and dichotomous variables as fixed factors. Results of hsTnT were entered log-transformed given their non-parametric distribution. To separate between generally available clinical variables and parameters only available by specific testing such as echocardiography or angiography, three different regression models were created (1st: only including clinical variables; 2nd: only including imaging variables; 3rd: all available variables). Statistical analyses were run with IBM SPSS Statistics, Version 22 (IBM Corp., Armonk, NY, USA).

\section{Results}

\section{STUDY POPULATION}

The distribution of hsTnT values on admission of the analysed 2,046 patients undergoing elective coronary angiography is shown in Figure 1. There was an exponential decrease in frequency with rising troponin levels. While 1,061 (52\%) patients presented with hsTnT above the lower limit of detection ( $5 \mathrm{ng} / \mathrm{L})$, only $315(15 \%)$ had an hsTnT above the $99^{\text {th }}$ percentile of a healthy population cut-off point (14 ng/L).

Patients with $\mathrm{hsTnT} \geq 5 \mathrm{ng} / \mathrm{L}$ at presentation were significantly older, more often male, had a higher proportion of clinical symptoms and cardiovascular risk factors such as diabetes mellitus and arterial hypertension, were more frequently on cardiovascular drugs such as ACE inhibitors and statins, and more often had a history of previous coronary events (Table 1). These patients were also more frequently diagnosed with obstructive coronary heart disease and demonstrated a higher proportion of reduced left ventricular (LV) ejection fraction, higher LV mass as well as more significant valvular heart disease and pulmonary hypertension during echocardiographic assessment.

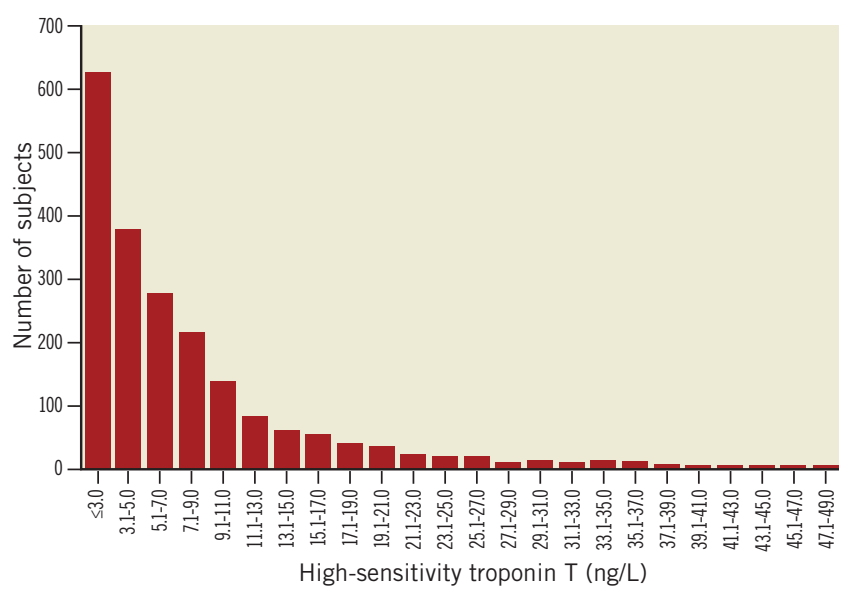

Figure 1. Distribution of high-sensitivity troponin T values.
From the $15 \%$ of patients with hsTnT above the $99^{\text {th }}$ percentile of a healthy population cut-off point, $19 \%$ were diagnosed without obstructive coronary heart disease.

\section{UNADJUSTED ANALYSES}

The distribution of troponin levels according to levels of various variables is shown in Figure 2 and Figure 3. For most variables, significant differences between different strata were found. However, these differences were numerically small for many of the evaluated variables. Only in patients with haemoglobin $\leq 10 \mathrm{~g} /$ $\mathrm{dL}$, creatinine clearance of less than $30 \mathrm{ml} / \mathrm{min}$, LV ejection fraction of less than $30 \%$, severe valvular heart disease, or severe pulmonary hypertension were median hsTnT levels above the $99^{\text {th }}$ percentile of a healthy population $(14 \mathrm{ng} / \mathrm{L})$.

\section{ADJUSTED ANALYSES}

To identify predictors generally available in clinical routine, the first multivariable model included only clinical variables. In this model, gender followed by age, renal function, diabetes, history of myocardial infarction, and haemoglobin levels were the variables most strongly associated with levels of cardiac troponin (Table 2).

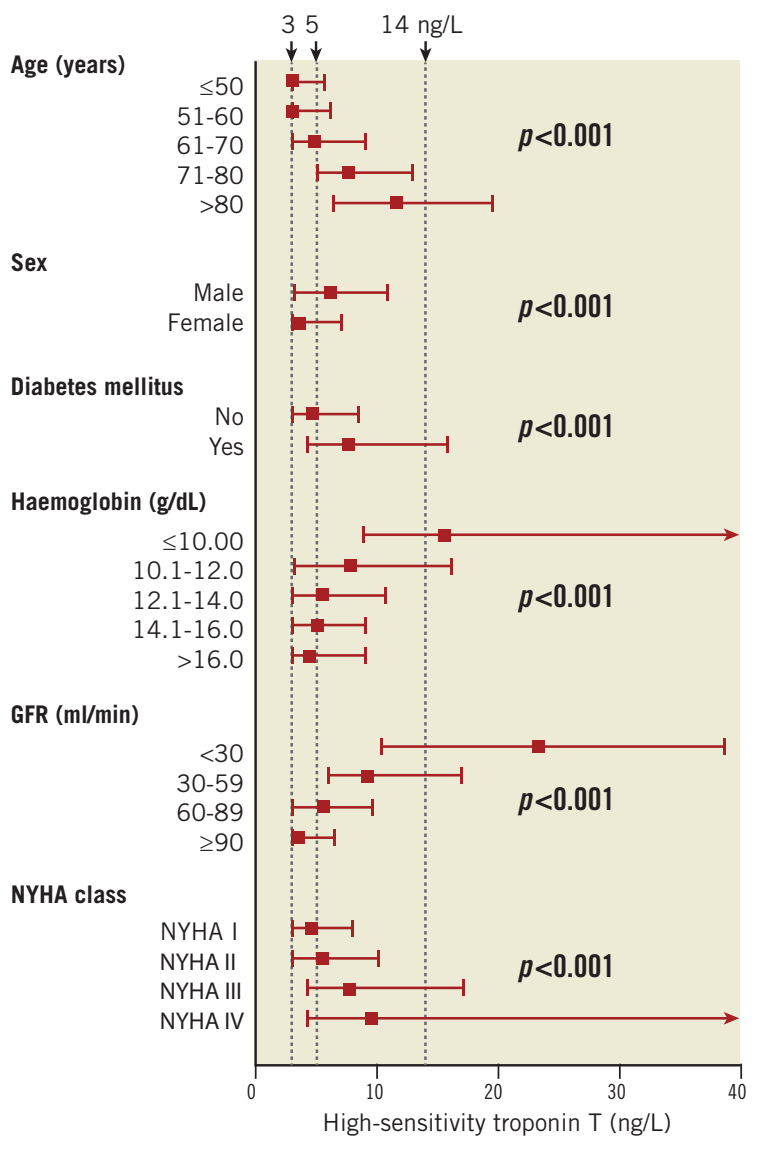

Figure 2. High-sensitivity troponin T level according to age, laboratory, and angiographic variables. Data presented as median with quartiles. GFR: glomerular filtration rate; NYHA: New York Heart Association 
Table 1. Baseline characteristics.

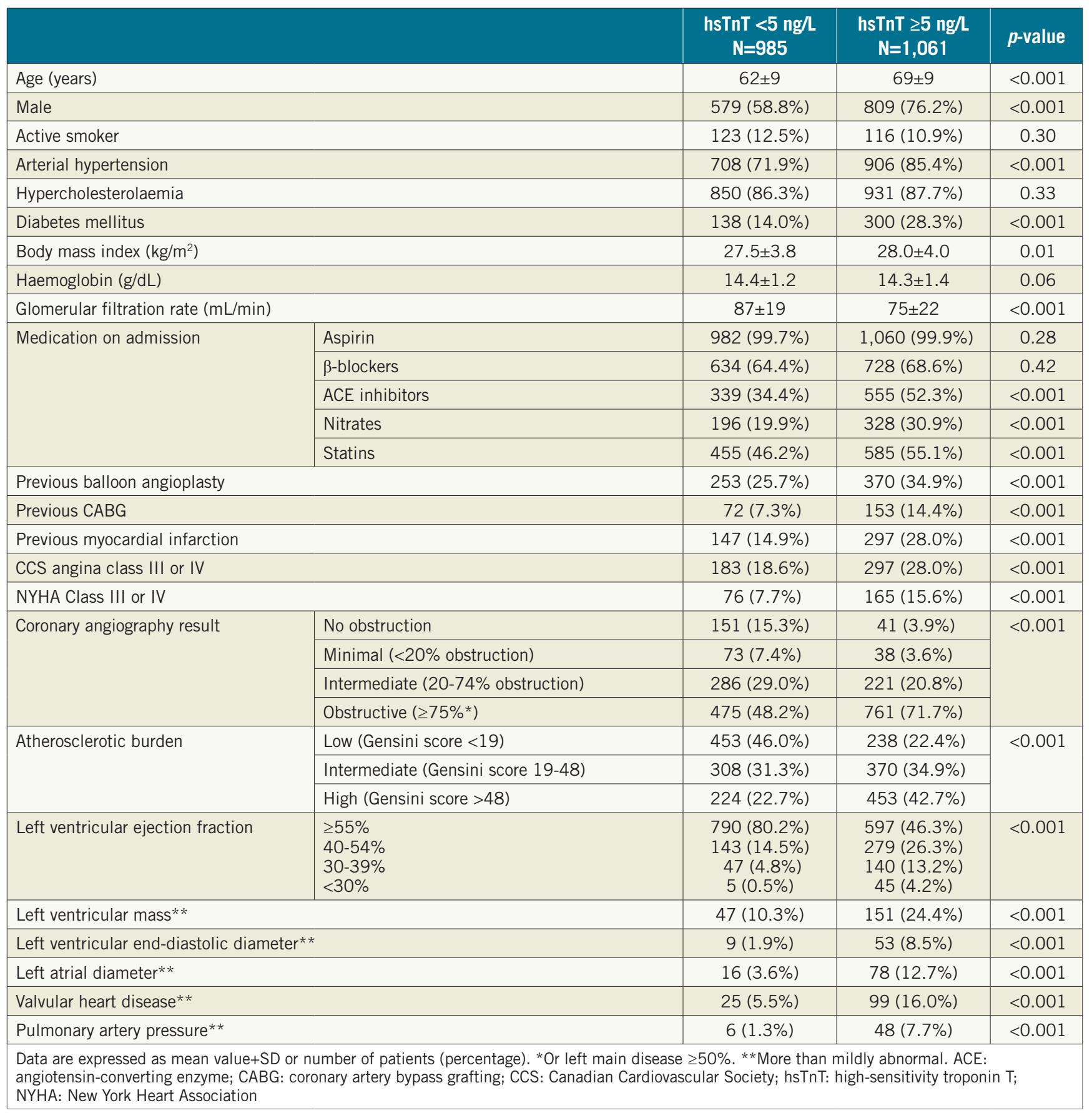

The second model included only angiographic and echocardiographic parameters. In this model, results of coronary angiography represented by Gensini score followed by LV ejection fraction, and LV mass demonstrated the highest strength of association with troponin levels.

In the combined analysis of all available variables (3rd model), gender followed by renal function, age, LV ejection fraction, LV mass, diabetes, and coronary angiography results showed the strongest association with levels of hsTnT. Further independent predictors of levels of hsTnT were haemoglobin, NYHA class, and smoking status.

\section{Discussion}

The implementation of high-sensitivity cardiac troponin assays into clinical routine did not only improve the diagnosis of acute $\mathrm{MI}^{1}$, but also for the first time allowed the detection of troponin levels in a significant proportion of stable patients ${ }^{6-8}$. In some of these stable patients even troponin levels above the $99^{\text {th }}$ percentile of a reference population were seen - the cut-off usually used for diagnosis of $\mathrm{MI}^{14}$. In patients presenting at an emergency department with acute diseases outside the setting of acute coronary syndromes, the proportion of patients with high-sensitivity cardiac troponin levels above the $99^{\text {th }}$ percentile can be up to $44 \%{ }^{19}$. 
Table 2. Multivariable linear regression for high-sensitivity troponin T levels at presentation.

\begin{tabular}{|c|c|c|c|c|c|c|}
\hline & \multicolumn{2}{|c|}{ Clinical parameters } & \multicolumn{2}{|c|}{$\begin{array}{c}\text { Angiographic/echocardiographic } \\
\text { parameters }\end{array}$} & \multicolumn{2}{|c|}{ Combined } \\
\hline & partial $\eta^{2}$ & $p$-value & partial $\eta^{2}$ & $p$-value & partial $\eta^{2}$ & $p$-value \\
\hline Age & 0.068 & $<0.001$ & & & 0.045 & $<0.001$ \\
\hline Male gender & 0.089 & $<0.001$ & & & 0.057 & $<0.001$ \\
\hline Active smoker & 0.009 & $<0.001$ & & & 0.006 & 0.020 \\
\hline Arterial hypertension & 0.002 & 0.030 & & & 0.003 & 0.104 \\
\hline Hypercholesterolaemia & $<0.001$ & 0.399 & & & 0.001 & 0.307 \\
\hline Diabetes mellitus & 0.016 & $<0.001$ & & & 0.014 & $<0.001$ \\
\hline Body mass index & $<0.001$ & 0.461 & & & $<0.001$ & 0.880 \\
\hline Haemoglobin & 0.010 & $<0.001$ & & & 0.007 & 0.010 \\
\hline LDL cholesterol & $<0.001$ & 0.675 & & & 0.001 & 0.437 \\
\hline Glomerular filtration rate & 0.059 & $<0.001$ & & & 0.053 & $<0.001$ \\
\hline \multicolumn{7}{|l|}{ Medication on admission } \\
\hline Aspirin & $<0.001$ & 0.953 & & & $<0.001$ & 0.999 \\
\hline$\beta$-blockers & 0.002 & 0.044 & & & 0.004 & 0.050 \\
\hline ACE inhibitors & 0.007 & $<0.001$ & & & 0.002 & 0.189 \\
\hline Nitrates & $<0.001$ & 0.601 & & & $<0.001$ & 0.991 \\
\hline Statins & $<0.001$ & 0.909 & & & 0.001 & 0.446 \\
\hline Previous balloon angioplasty & 0.001 & 0.160 & & & 0.002 & 0.131 \\
\hline Previous CABG & $<0.001$ & 0.530 & & & 0.003 & 0.083 \\
\hline Previous myocardial infarction & 0.011 & $<0.001$ & & & $<0.001$ & 0.956 \\
\hline CCS angina class & 0.003 & 0.023 & & & 0.002 & 0.156 \\
\hline NYHA class & 0.007 & $<0.001$ & & & 0.006 & 0.015 \\
\hline Atherosclerotic burden (Gensini score)* & & & 0.055 & $<0.001$ & 0.014 & 0.001 \\
\hline Left ventricular ejection fraction & & & 0.044 & $<0.001$ & 0.024 & $<0.001$ \\
\hline Left ventricular mass & & & 0.019 & $<0.001$ & 0.015 & 0.002 \\
\hline Left ventricular end-diastolic diameter & & & 0.004 & 0.230 & 0.005 & 0.203 \\
\hline Left atrial diameter & & & 0.004 & 0.209 & 0.002 & 0.598 \\
\hline Valvular heart disease & & & 0.002 & 0.650 & 0.002 & 0.670 \\
\hline Predominantly aortic valve affected & & & 0.001 & 0.751 & 0.002 & 0.605 \\
\hline Pulmonary artery pressure & & & 0.007 & 0.055 & 0.004 & 0.327 \\
\hline
\end{tabular}

Since elevated levels of troponin can indicate acute MI or at least increased risk of cardiovascular events ${ }^{7-9,11}$, many of these patients undergo coronary assessment, which might be unnecessary in a significant proportion of these patients.

The present study demonstrated that more than half of stable patients undergoing elective coronary angiography have detectable levels of cardiac troponin and approximately $15 \%$ of patients present with troponin levels even above the $99^{\text {th }}$ percentile of a reference population - without having acute MI according to current definition ${ }^{14}$. Roughly $30 \%$ of patients with detectable levels of cardiac troponin and $20 \%$ of patients with troponin levels even above the $99^{\text {th }}$ percentile did not have an obstructive coronary heart disease. Important features of the present analysis are the use of a large cohort with more than 2,000 patients, the availability of echocardiographic and angiographic data, and multivariable analyses identifying the strength of association of variables with levels of cardiac troponin. Key findings are that changes in cardiac troponin were statistically significant but numerically small for many variables. Only haemoglobin $\leq 10 \mathrm{~g} / \mathrm{dL}$, creatinine clearance of less than $30 \mathrm{ml} / \mathrm{min}$, LV ejection fraction of less than $30 \%$, severe valvular heart disease, and severe pulmonary hypertension were associated with median hsTnT levels above the $99^{\text {th }}$ percentile of a reference population. Multivariable analyses demonstrated that strength of association weakened for multiple previously described variables after adjustment for clinical and imaging data. The variables most strongly associated with levels of cardiac troponin after adjustment were age, gender, renal function, and LV ejection fraction.

Several previous studies have investigated the association of levels of cardiac troponin with multiple variables. Cardiovascular disorders linked to elevations of troponin are, among others, left ventricular wall stress and dysfunction, heart failure with preserved ejection fraction, aortic stenosis, hypertension, acute heart failure, and coronary artery disease $\mathrm{e}^{20-23}$. For example, a recent study demonstrated that more than $50 \%$ of patients with heart 


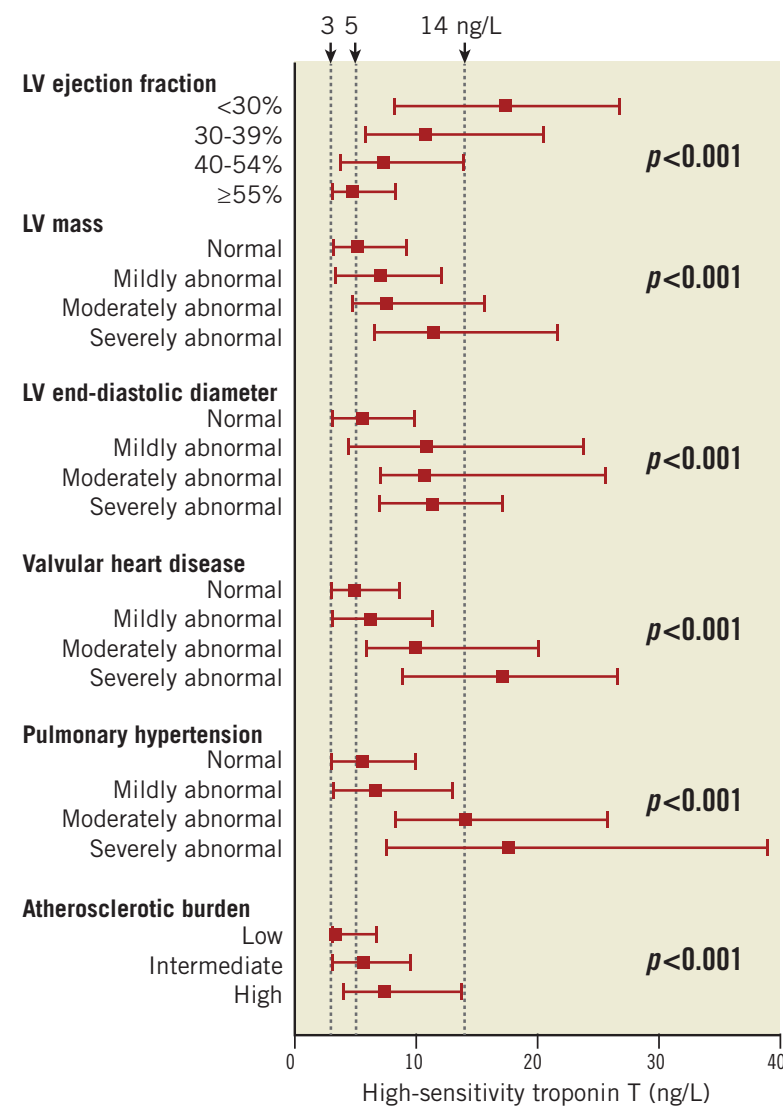

Figure 3. High-sensitivity troponin T level according to clinical variables. Data presented as median with quartiles. Atherosclerotic burden quantified by Gensini score. LV: left ventricular

failure with preserved ejection fraction had troponin levels above the cut-off for diagnosis of myocardial infarction ${ }^{20}$. In patients with aortic valve disease, the mean level of cardiac troponin was found to be higher as compared to patients without aortic valve disease ${ }^{22}$. Troponin levels have also been associated with the severity of coronary artery disease outside the setting of acute coronary syndromes ${ }^{24}$, and with the presence of vulnerable plaques $^{23}$. A recent imaging study using CT and SPECT demonstrated that levels of cardiac troponin can be used for discrimination of patients with and without structural heart disease in general $^{25}$.

Apart from cardiovascular disorders, variables such as age, gender, renal function, chronic obstructive pulmonary disease, anaemia, and diabetes have been linked to elevated levels of cardiac troponin $^{21,26-30}$. For example, patients with stable chronic obstructive pulmonary disease were found to have more than twofold higher levels of cardiac troponin as compared to the general population ${ }^{28}$. In the setting of acute exacerbation of chronic obstructive pulmonary disease, an approximately fourfold increase in levels of troponin was found as compared to patients with stable disease ${ }^{31}$. The mechanisms behind elevations of troponin in patients apparently without cardiovascular disease are not completely understood, but might include subclinical myocardial injury caused by stress, hypotension, or - as demonstrated by a recent analysis - impaired coronary flow reserve reflecting microvascular dysfunction ${ }^{32}$.

The results of the present analysis are in line with most of the previous findings. However, after adjustment for echocardiographic and angiographic parameters, several variables were not predictive for levels of hsTnT anymore such as drugs commonly prescribed for heart failure, history of myocardial infarction, and imaging parameters such as diameters, and valvular heart disease. Other parameters such as findings of coronary angiography demonstrated a weaker strength of association with levels of cardiac troponin after adjustment for clinical variables but prevailed as independent predictors. The variables most strongly associated with elevated levels were male gender followed by renal function, age, LV ejection fraction, diabetes, LV mass, and coronary status.

\section{Limitations}

This analysis is retrospective with all the adherent limitations. Since only patients admitted for elective coronary angiography were enrolled, the present data cannot be extrapolated to the overall population. Only parameters available from the clinical records could be analysed. Thus, transient and/or undiagnosed alterations such as hypertension or tachycardia not recorded by the staff and potentially leading to a rise in cardiac troponin cannot be fully excluded.

\section{Conclusions}

Approximately $15 \%$ of stable subjects admitted for elective coronary angiography present with hsTnT levels above the upper reference limit of normal. However, a fifth of these patients are not diagnosed with obstructive coronary heart disease. The variables most strongly associated with elevated levels were male gender followed by renal function, age, LV ejection fraction, diabetes, LV mass, and coronary status. The significant variation of troponin levels according to different variables shown in this analysis might provide some guidance for a more differentiated interpretation of this biomarker.

\section{Impact on daily practice}

Approximately $15 \%$ of stable subjects admitted for elective coronary angiography present with hsTnT levels above the upper reference limit of normal. However, a fifth of these patients are not diagnosed with obstructive coronary heart disease. The variables most strongly associated with elevated levels were male gender, renal function, age, LV ejection fraction, diabetes, and LV mass, followed by coronary status. Since, in daily routine, elevated levels of hsTnT are often seen as a trigger for invasive coronary assessment, the present data might provide some guidance for a more differentiated interpretation of the association of this biomarker with various clinical variables and outcomes.

\section{Funding}

This work was supported by Roche Diagnostics by provision of laboratory kits for high-sensitivity troponin $\mathrm{T}$. 


\section{Conflict of interest statement}

C. Stratz reports receiving speaker's honoraria from Eli Lilly. D. Trenk reports receiving speaker's honoraria from AstraZeneca, Bayer, Boehringer Ingelheim, Bristol Myers Squibb, Daiichi Sankyo, Eli Lilly, MSD, and Pfizer; and consulting fees from AstraZeneca, Bayer, Boehringer Ingelheim, Daiichi Sankyo, Eli Lilly and Otsuka. M. Ferenc reports receiving speaker's honoraria from AstraZeneca, Eli Lilly, Biotronik, Medtronic, Abbott Vascular, and Biosensors. W. Hochholzer reports receiving speaker's honoraria from Daiichi Sankyo, AstraZeneca, and Boehringer Ingelheim. The other authors have no conflicts of interest to declare.

\section{References}

1. Hochholzer W, Morrow DA, Giugliano RP. Novel biomarkers in cardiovascular disease: update 2010. Am Heart J. 2010;160: 583-94.

2. Amsterdam EA, Wenger NK, Brindis RG, Casey DE Jr, Ganiats TG, Holmes DR Jr, Jaffe AS, Jneid H, Kelly RF, Kontos MC, Levine GN, Liebson PR, Mukherjee D, Peterson ED, Sabatine MS, Smalling RW, Zieman SJ; American College of Cardiology; American Heart Association Task Force on Practice Guidelines; Society for Cardiovascular Angiography and Interventions; Society of Thoracic Surgeons; American Association for Clinical Chemistry. 2014 AHA/ACC Guideline for the Management of Patients with Non-ST-Elevation Acute Coronary Syndromes: a report of the American College of Cardiology/American Heart Association Task Force on Practice Guidelines. J Am Coll Cardiol. 2014;64: e139-228.

3. Hamm CW, Bassand JP, Agewall S, Bax J, Boersma E, Bueno H, Caso P, Dudek D, Gielen S, Huber K, Ohman M, Petrie MC, Sonntag F, Uva MS, Storey RF, Wijns W, Zahger D; ESC Committee for Practice Guidelines. ESC Guidelines for the management of acute coronary syndromes in patients presenting without persistent ST-segment elevation: The Task Force for the management of acute coronary syndromes (ACS) in patients presenting without persistent ST-segment elevation of the European Society of Cardiology (ESC). Eur Heart J. 2011;32:2999-3054.

4. Stratz C, Amann M, Berg DD, Morrow DA, Neumann FJ, Hochholzer W. Novel biomarkers in cardiovascular disease: research tools or ready for personalized medicine? Cardiol Rev. 2012;20:111-7.

5. Keller T, Zeller T, Ojeda F, Tzikas S, Lillpopp L, Sinning C, Wild P, Genth-Zotz S, Warnholtz A, Giannitsis E, Mockel M, Bickel C, Peetz D, Lackner K, Baldus S, Munzel T, Blankenberg S. Serial changes in highly sensitive troponin I assay and early diagnosis of myocardial infarction. JAMA. 2011;306:2684-93.

6. Wang TJ, Wollert KC, Larson MG, Coglianese E, McCabe EL, Cheng S, Ho JE, Fradley MG, Ghorbani A, Xanthakis V, Kempf T, Benjamin EJ, Levy D, Vasan RS, Januzzi JL. Prognostic utility of novel biomarkers of cardiovascular stress: the Framingham Heart Study. Circulation. 2012;126:1596-604.

7. de Lemos JA, Drazner MH, Omland T, Ayers CR, Khera A, Rohatgi A, Hashim I, Berry JD, Das SR, Morrow DA, McGuire DK.
Association of troponin $\mathrm{T}$ detected with a highly sensitive assay and cardiac structure and mortality risk in the general population. JAMA. 2010;304:2503-12.

8. deFilippi CR, de Lemos JA, Christenson RH, Gottdiener JS, Kop WJ, Zhan M, Seliger SL. Association of serial measures of cardiac troponin $\mathrm{T}$ using a sensitive assay with incident heart failure and cardiovascular mortality in older adults. JAMA. 2010;304: 2494-502.

9. Everett BM, Cook NR, Magnone MC, Bobadilla M, Kim E, Rifai N, Ridker PM, Pradhan AD. Sensitive cardiac troponin T assay and the risk of incident cardiovascular disease in women with and without diabetes mellitus: the Women's Health Study. Circulation. 2011;123:2811-8.

10. Ndrepepa G, Braun S, Mehilli J, Birkmeier KA, Byrne RA, Ott I, Hosl K, Schulz S, Fusaro M, Pache J, Hausleiter J, Laugwitz KL, Massberg S, Seyfarth M, Schömig A, Kastrati A. Prognostic value of sensitive troponin $\mathrm{T}$ in patients with stable and unstable angina and undetectable conventional troponin. Am Heart J. 2011;161:68-75.

11. Hochholzer W, Valina CM, Stratz C, Amann M, Schlittenhardt D, Buttner HJ, Trenk D, Neumann FJ. Highsensitivity cardiac troponin for risk prediction in patients with and without coronary heart disease. Int J Cardiol. 2014;176:444-9.

12. Trenk D, Hochholzer W, Fromm MF, Chialda LE, Pahl A, Valina CM, Stratz C, Schmiebusch P, Bestehorn HP, Buttner HJ, Neumann FJ. Cytochrome P450 2C19 681G>A polymorphism and high on-clopidogrel platelet reactivity associated with adverse 1-year clinical outcome of elective percutaneous coronary intervention with drug-eluting or bare-metal stents. $J$ Am Coll Cardiol. 2008;51:1925-34.

13. Hochholzer W, Trenk D, Bestehorn HP, Fischer B, Valina CM, Ferenc M, Gick M, Caputo A, Buttner HJ, Neumann FJ. Impact of the degree of peri-interventional platelet inhibition after loading with clopidogrel on early clinical outcome of elective coronary stent placement. J Am Coll Cardiol. 2006;48:1742-50.

14. Thygesen K, Alpert JS, Jaffe AS, Simoons ML, Chaitman BR, White HD; Writing Group on the Joint ESC/ACCF/AHA/WHF Task Force for the Universal Definition of Myocardial Infarction, Thygesen K, Alpert JS, White HD, Jaffe AS, Katus HA, Apple FS, Lindahl B, Morrow DA, Chaitman BA, Clemmensen PM, Johanson P, Hod H, Underwood R, Bax JJ, Bonow RO, Pinto F, Gibbons RJ, Fox KA, Atar D, Newby LK, Galvani M, Hamm CW, Uretsky BF, Gabriel Steg P, Wijns W, Bassand JP, Menasche P, Ravkilde J, Ohman EM, Antman EM, Wallentin LC, Armstrong PW, Januzzi JL, Nieminen MS, Gheorghiade M, Filippatos G, Luepker RV, Fortmann SP, Rosamond WD, Levy D, Wood D, Smith SC, Hu D, Lopez-Sendon JL, Robertson RM, Weaver D, Tendera M, Bove AA, Parkhomenko AN, Vasilieva EJ, Mendis S; ESC Committee for Practice Guidelines (CPG). Third universal definition of myocardial infarction. Eur Heart J. 2012;33:2551-67.

15. Giannitsis E, Kurz K, Hallermayer K, Jarausch J, Jaffe AS, Katus HA. Analytical validation of a high-sensitivity cardiac troponin T assay. Clin Chem. 2010;56:254-61. 
16. Lang RM, Badano LP, Mor-Avi V, Afilalo J, Armstrong A, Ernande L, Flachskampf FA, Foster E, Goldstein SA, Kuznetsova T, Lancellotti P, Muraru D, Picard MH, Rietzschel ER, Rudski L, Spencer KT, Tsang W, Voigt JU. Recommendations for cardiac chamber quantification by echocardiography in adults: an update from the American Society of Echocardiography and the European Association of Cardiovascular Imaging. Eur Heart J Cardiovasc Imaging. 2015;16:233-70.

17. Gensini GG. A more meaningful scoring system for determining the severity of coronary heart disease. Am J Cardiol. 1983; 51:606.

18. Neeland IJ, Patel RS, Eshtehardi P, Dhawan S, McDaniel MC, Rab ST, Vaccarino V, Zafari AM, Samady H, Quyyumi AA. Coronary angiographic scoring systems: an evaluation of their equivalence and validity. Am Heart J. 2012;164:547-552.e1.

19. Jairam S, Jones P, Samaraie L, Chataline A, Davidson J, Stewart R. Clinical diagnosis and outcomes for Troponin T 'positive' patients assessed by a high sensitivity compared with a 4th generation assay. Emerg Med Australas. 2011;23:490-501.

20. Jhund PS, Claggett BL, Voors AA, Zile MR, Packer M, Pieske BM, Kraigher-Krainer E, Shah AM, Prescott MF, Shi V, Lefkowitz M, McMurray JJ, Solomon SD; PARAMOUNT Investigators. Elevation in high-sensitivity troponin $\mathrm{T}$ in heart failure and preserved ejection fraction and influence of treatment with the angiotensin receptor neprilysin inhibitor LCZ696. Circ Heart Fail. 2014;7:953-9.

21. Schulz O, Reinicke M, Berghoefer GH, Bensch R, Kraemer J, Schimke I, Jaffe AS. High-sensitive cardiac troponin I (hs-cTnI) values in patients with stable cardiovascular disease: an initial foray. Clin Chim Acta. 2010;411:812-7.

22. Nunes JP, Mota Garcia JM, Farinha RM, Carlos Silva J, Magalhaes D, Vidal Pinheiro L, Abreu Lima C. Cardiac troponin I in aortic valve disease. Int J Cardiol. 2003;89:281-5.

23. Korosoglou G, Lehrke S, Mueller D, Hosch W, Kauczor HU, Humpert PM, Giannitsis E, Katus HA. Determinants of troponin release in patients with stable coronary artery disease: insights from CT angiography characteristics of atherosclerotic plaque. Heart. 2011;97:823-31.
24. Ndrepepa G, Braun S, Schulz S, Mehilli J, Schömig A, Kastrati A. High-sensitivity troponin $\mathrm{T}$ level and angiographic severity of coronary artery disease. Am J Cardiol. 2011;108: 639-43.

25. Schlett CL, Truong QA, Ahmed W, Blankstein R, Ferencik M, Uthamalingam S, Bamberg F, Koenig W, Januzzi JL, Hoffmann U. High-sensitivity troponin $\mathrm{T}$ and C-reactive protein to identify patients without cardiac structural and functional abnormalities as assessed by cardiac CT and SPECT imaging: can biomarkers predict cardiac health? Int J Cardiovasc Imaging. 2013;29:865-73.

26. Januzzi JL Jr, Filippatos G, Nieminen M, Gheorghiade M. Troponin elevation in patients with heart failure: on behalf of the third Universal Definition of Myocardial Infarction Global Task Force: Heart Failure Section. Eur Heart J. 2012;33:2265-71.

27. Selvin E, Lazo M, Chen Y, Shen L, Rubin J, McEvoy JW, Hoogeveen RC, Sharrett AR, Ballantyne CM, Coresh J. Diabetes mellitus, prediabetes, and incidence of subclinical myocardial damage. Circulation. 2014;130:1374-82.

28. Neukamm AM, Hoiseth AD, Hagve TA, Soyseth V, Omland T. High-sensitivity cardiac troponin $\mathrm{T}$ levels are increased in stable COPD. Heart. 2013;99:382-7.

29. Ralli S, Horwich TB, Fonarow GC. Relationship between anemia, cardiac troponin I, and B-type natriuretic peptide levels and mortality in patients with advanced heart failure. Am Heart J. 2005;150:1220-7.

30. Bellotto F, Fagiuoli S, Pavei A, Gregory SA, Cati A, Silverj E, Plebani M, Zaninotto M, Mancuso T, Iliceto S. Anemia and ischemia: myocardial injury in patients with gastrointestinal bleeding. Am J Med. 2005;118:548-51.

31. Soyseth V, Bhatnagar R, Holmedahl NH, Neukamm A, Hoiseth AD, Hagve TA, Einvik G, Omland T. Acute exacerbation of COPD is associated with fourfold elevation of cardiac troponin $\mathrm{T}$. Heart. 2013;99:122-6.

32. Taqueti VR, Everett BM, Murthy VL, Gaber M, Foster CR, Hainer J, Blankstein R, Dorbala S, Di Carli MF. Interaction of impaired coronary flow reserve and cardiomyocyte injury on adverse cardiovascular outcomes in patients without overt coronary artery disease. Circulation. 2015;131:528-35. 